\title{
Magnitude determination using duration of high frequency energy radiation and displacement amplitude: application to the 2011 off the Pacific coast of Tohoku Earthquake
}

\author{
Tatsuhiko Hara \\ International Institute of Seismology and Earthquake Engineering, Building Research Institute, \\ 1 Tatehara, Tsukuba, Ibaraki 305-0802, Japan \\ (Received April 7, 2011; Revised May 17, 2011; Accepted May 18, 2011; Online published September 27, 2011)
}

\begin{abstract}
We have applied a technique to determine earthquake magnitudes, using durations of high frequency energy radiation and the maximum displacement amplitudes, to the 2011 off the Pacific coast of Tohoku Earthquake. The estimated duration of high frequency energy radiation and magnitude are $170.5 \mathrm{~s}$, and 8.96, respectively. This agrees well with preliminary analyses for this earthquake. Compared with the December 26, 2004, Sumatra earthquake $\left(M_{\mathrm{w}} 9.0\right)$, this event is characterized by a shorter duration of high frequency energy radiation and a larger displacement amplitude. The measured durations of high frequency energy radiation show azimuthal dependence, which indicates rupture propagation in the southwest direction. This result, together with rupture models obtained by other studies using lower frequency seismic signals or tsunami waveforms, suggests that there were two distinct rupture propagations in this event: one in a southwest direction from which high frequency energies were radiated efficiently, and the other in an east direction from which a very large seismic moment was released. We measured the time differences between $P$-wave arrivals and the times at which the absolute amplitudes of high bandpass $(2-4 \mathrm{~Hz}$ ) filtered $P$-waves became the largest. Most of the measured time differences, normalized by twice the centroid time shift, are in the range between 50 and 80 per cent. This is consistent with the frequency distribution that we obtained previously for a set of 68 large shallow earthquakes.

Key words: High-frequency energy radiation, magnitude, rupture propagation.
\end{abstract}

\section{Introduction}

Hara (2007a) developed a method to determine earthquake magnitudes using durations of high frequency energy radiation, which we refer to as HFER hereafter, and maximum displacement amplitudes measured from first arriving $P$-waves recorded at a tele-seismic distance range. He showed that this method was applicable to huge earthquakes such as the December 26, 2004, Sumatra earthquake $\left(M_{\mathrm{w}} 9.0\right.$ after the Global Centroid Moment Tensor Project, which we refer to as GCMT hereafter).

The mega-thrust earthquake occurred on March 11, 2011 (origin time $14: 46: 18.1 \mathrm{JST}$; location $38.10^{\circ} \mathrm{N}, 142.86^{\circ} \mathrm{E}$; depth $24 \mathrm{~km} ; M_{\mathrm{w}}$ 9.0: Japan Meteorological Agency, JMA) and caused huge tsunamis and devastating damage in the northeast part of Japan. In the present study, we have applied the method of Hara (2007a) to this event. When the earthquake occurred, we were in Tokyo away from our institute located in Tsukuba. Since transportation facilities were down, we could not start data analyses immediately. We obtained a set of estimates of HFER duration and magnitude on the 13th in Tsukuba. The estimates of HFER duration and magnitude shown in this paper are those determined on that day. In April, we compared the results of

Copyright (c) The Society of Geomagnetism and Earth, Planetary and Space Sciences (SGEPSS); The Seismological Society of Japan; The Volcanological Society of Japan; The Geodetic Society of Japan; The Japanese Society for Planetary Sciences; TERRAPUB.

doi:10.5047/eps.2011.05.014 this event with those of other large earthquakes considered in our previous works and we investigated the azimuthal dependence of durations of HFER, which we also present in this study. We also investigated the time differences between $P$-wave arrivals and the times at which the absolute amplitudes of high bandpass (2-4 Hz) filtered $P$-waves became the largest. Hara (2008) analyzed 68 large shallow earthquakes to show that the frequency of these time differences, normalized by twice centroid time shifts of the corresponding earthquakes, was high around 50\% (corresponding to centroid time shifts).

\section{Durations of HFER}

We retrieved BHZ channel waveform data, recorded at the Global Seismograph Network (GSN) stations, from IRIS DMC (Incorporated Research Institutions for Seismology, Data Management Center). We analyzed data from stations in the epicentral distance range of 30-85 degrees to avoid scattering due to the upper mantle or $\mathrm{D}^{\prime \prime}$ structures (Shearer and Earle, 2004). Following the data processing procedure of Hara (2007a), we determined the duration of HFER using band-pass filtering (corner frequencies are 2 and $4 \mathrm{~Hz}$ ), calculation of squares, and applying a moving window average for smoothing (the moving window is centered around each data point). The end time of HFER was chosen to be the time when the amplitude of the smoothed time series became smaller than 25 per cent of its maximum value. The details are described in Hara (2007a). 


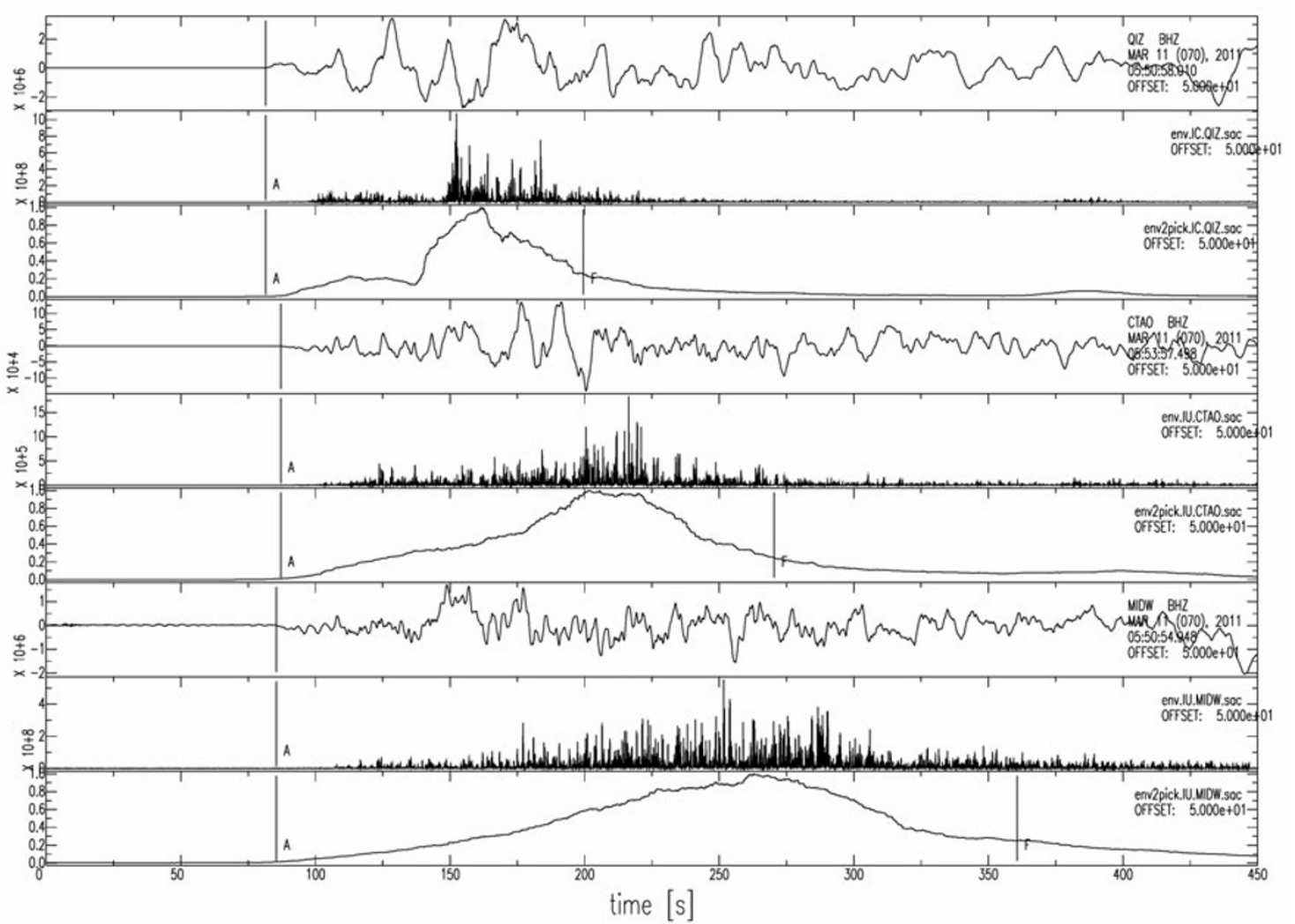

Fig. 1. Examples of measurements of HFER for the 2011 off the Pacific coast of Tohoku Earthquake. The upper, middle, and lower three traces are the results for three stations, QIZ, CTAO, and MIDW, respectively. The epicentral distances and azimuths are 34.2 and 245.0 degrees for QIZ, 58.2 and 175.7 degrees for CTAO, and 34.8 and 94.6 degrees for MIDW, respectively. For each station, three traces are shown; they are an observed seismogram (upper trace), a time series of squares of band-pass (2-4 Hz) filtered seismogram (middle trace), and its smoothed time series normalized by the maximum value (lower trace), respectively. "A" and "F" in the smoothed time series denote the arrivals of $P$-waves and the estimated ends of HFER, respectively.

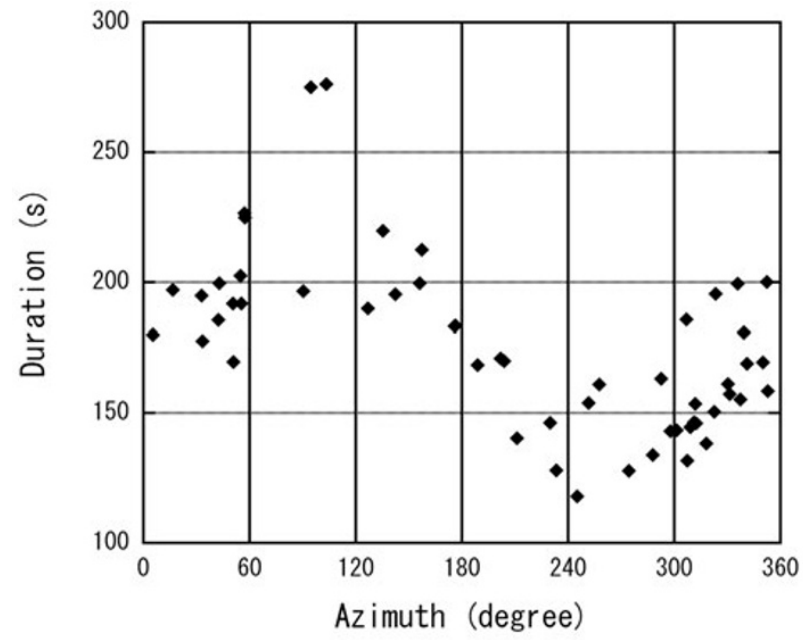

Fig. 2. Durations of HFER are shown as a function of azimuths.

Figure 1 shows examples of duration measurements. The HFER durations estimated for the stations shown in Fig. 1 are 118.1, 183.3, and 275.2 s for stations QIZ, CTAO, and MIDW, respectively. The median of the measured durations for all of the stations is $170.5 \mathrm{~s}$. As Hara (2007a) has shown, this can be a rough estimate for the source duration time and our result is consistent with preliminary analyses such as Hayes (2011) and Shao et al. (2011).

The measured durations show a clear azimuthal dependence (Fig. 2). The shorter durations around 240 degrees indicates that the rupture propagated in a southwest direction. This is consistent with the results of back projection of rupture by Ishii (2011) and Wang and Mori (2011), and partly consistent with the high frequency analysis of Chu and Helmberger (2011).

\section{Magnitude}

We here calculated earthquake magnitudes using the following formula (Hara, 2007a):

$$
M=0.79 \log A+0.83 \log \Delta+0.69 \log t+6.47
$$

where $M$ is the earthquake magnitude, $A$ is the maximum displacement $(\mathrm{m})$ during the estimated duration of HFER from the arrival time of a $P$-wave, $\Delta$ is the epicentral distance $(\mathrm{km})$, and $t$ is the estimated duration (s) of HFER. The estimates of magnitude for the stations shown in Fig. 1 are 8.97, 8.71, and 8.79 for QIZ, CTAO, and MIDW, respectively. The median of magnitudes for all stations is 8.96. This agrees well with $M_{\mathrm{w}} 9.0$ issued by JMA (http://www.jma.go.jp/jma/press/1103/13b/201103131255. html) and from the USGS WPhase moment solution (http://earthquake.usgs.gov/earthquakes/eqinthenews/2011/ usc0001xgp/neic_c0001xgp_wmt.php), and 9.1 from the 


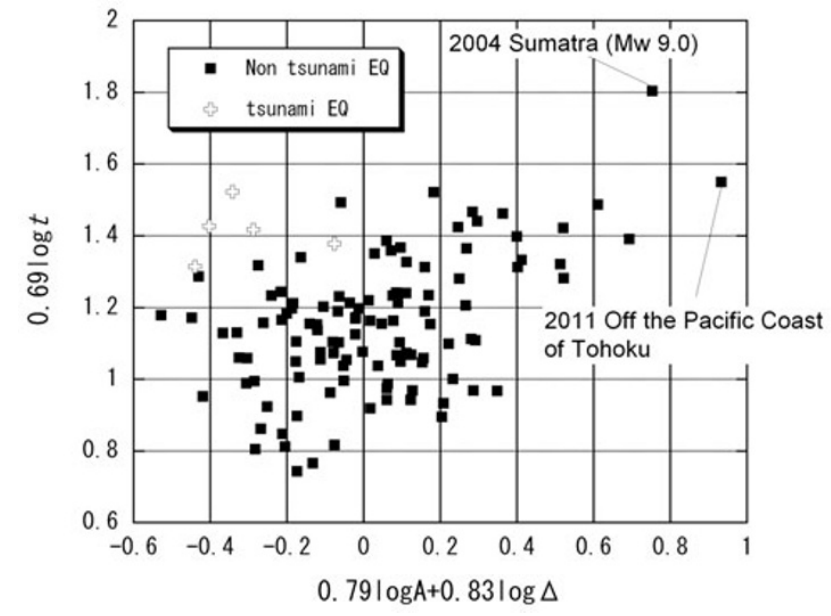

Fig. 3. Contributions to magnitudes from maximum displacement amplitudes and epicentral distances (the horizontal axis) and those from durations of HFER (the vertical axis) are plotted for events analyzed by Hara (2007a, b, 2009) and large $\left(M_{\mathrm{w}} \geq 7.2\right)$ shallow (depths $\left.\leq 50 \mathrm{~km}\right)$ earthquakes that occurred from July, 2006 to the 2011 off the Pacific coast of Tohoku Earthquake. Non-tsunami earthquakes and tsunami earthquakes are represented by solid squares and crosses, respectively. The 2011 off the Pacific coast of Tohoku Earthquake and the December 26, 2004, Sumatra earthquakes are identified.

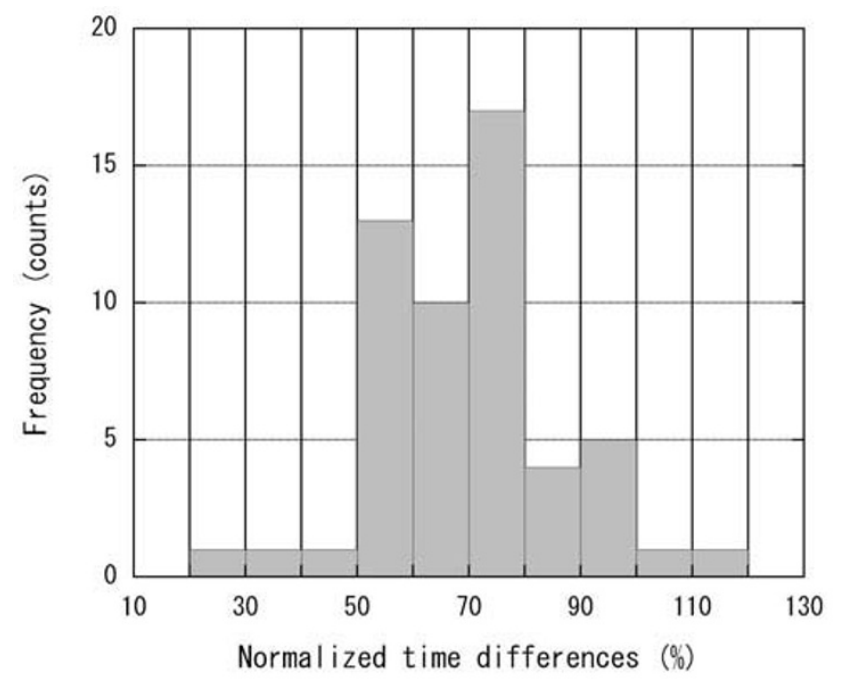

Fig. 4. The frequencies of normalized time differences between $P$-wave arrivals and the times at which the absolute amplitudes of high bandpass $(2-4 \mathrm{~Hz}$ ) filtered $P$-waves became the largest.

\section{GCMT.}

Figure 3 shows the contributions of the maximum amplitude with the distance correction (i.e. the first and second terms of the right-hand side of Eq. (1)) and the duration of HFER (the third term of the right-hand side of Eq. (1)), respectively, for events analyzed by Hara (2007a, $\mathrm{b}, 2009)$ and large $\left(M_{\mathrm{w}} \geq 7.2\right)$ shallow (depths $\left.\leq 50 \mathrm{~km}\right)$ earthquakes that occurred from July, 2006 to the 2011 off the Pacific coast of Tohoku Earthquake. The total number of events is 115. For the December 26, 2004, Sumatra earthquake ( $M_{\mathrm{w}} 9.0$ from the GCMT), Hara (2007a) determined that the duration of HFER and the magnitude were $396.2 \mathrm{~s}$ and 9.03, respectively. The duration of HFER of the 2011 off the Pacific coast of Tohoku Earthquake, 170.5 s, is shorter than that of the Sumatra earthquake (about 43 per cent), while the maximum amplitude with the distance correction is larger (about 169 per cent). Tsunami earthquakes (Kanamori, 1972) are characterized by small amplitudes and long durations (the crosses in Fig. 3). Thus, our result does not infer that the 2011 off the Pacific coast of Tohoku Earthquake was a tsunami earthquake, although it does not exclude the possibility that the rupture process had a tsunami earthquake-like component.

\section{Temporal Distribution of the Largest High Fre- quency Signals}

We measured the time differences between $P$-wave arrivals and the times at which the absolute amplitudes of high bandpass $(2-4 \mathrm{~Hz})$ filtered $P$-waves became the largest. Following Hara (2008), we normalized these time differences by twice the centroid time shift, $69.8 \mathrm{~s}$, from the GCMT. Most of the normalized time differences are in the range of 50 to 80 per cent (Fig. 4). The mean is 69.9 per cent (corresponding to $97.6 \mathrm{~s}$ ). This is consistent with the distribution obtained by Hara (2008), who showed that frequencies of these time differences are high around centroid time shifts (figures 3 and 4 in his paper). Thus, the result for this event again implies that HFER is weak in the vicinity of rupture starting regions.

\section{Discussion}

After the December 26, 2004, Sumatra earthquake occurred, many ideas and techniques have been proposed to determine reliable magnitudes more rapidly for tsunami early warning. For the 2011 off the Pacific coast of Tohoku Earthquake, INGV (Istituto Nazionale di Geofisica e Vulcanologia) obtained in real-time an $M_{\text {wpd }}$ (Lomax and Michelini, 2009) estimate of 8.5 at 12 minutes after the origin time, and a final $M_{\mathrm{wpd}} 8.8$ within 15 minutes after the origin time (Lomax and Michelini, 2011). When $M_{\mathrm{wpd}}$ with the "moment correction" of Lomax and Michelini (2009) is applied to a large set of off-line seismograms, the $M_{\text {wpd }}$ estimate is 9.0 (Anthony Lomax, personal communication). INGV obtained real-time estimates of high-frequency rupture duration $T_{0}$ of $143 \mathrm{~s}$ at 12 minutes after the origin time and a final $T_{0}$ of about $170 \mathrm{~s}$ within 15 minutes after the origin time (Lomax and Michelini, 2011). USGS obtained an $M_{\mathrm{w}}$ estimate of 8.9 from Wphase moment tensor (Kanamori and Rivera, 2008) 34 minutes after the origin time (“Tohoku, Japan 2011 M 9.0 Educational Slides", http:// earthquake.usgs.gov/learn/topics/Tohoku2011.ppt). GFZ (Deutsches GeoForschungsZentrum) obtained an $M_{\mathrm{w}}\left(m_{\mathrm{B}}\right)$ (Bormann and Saul, 2008) estimate of 8.6, 8 minutes after the origin time (Joachim Saul, personal communication). Since $m_{\mathrm{B}}$ is derived from a single maximum velocity amplitude, this technique is simpler and also slightly faster than methods involving additional measurements of rupture duration. Thus, all these techniques worked well for the 2011 off the Pacific coast of Tohoku Earthquake mainly using tele-seismic data, although $M_{\mathrm{w}}\left(m_{\mathrm{B}}\right)$ was smaller than others.

The initial $M_{\mathrm{wp}}$ (Tsuboi et al., 1995, 1999; Whitmore et al., 2002) estimate reported by PTWC (Pacific Tsunami Warning Center) was 7.9 
(http://ptwc.weather.gov/ptwc/?region=1\&id=pacific. 2011 . 03.11.055508), which is much smaller than the value of $M_{\mathrm{w}}$ 9.0-9.1 issued by JMA, USGS, and GCMT. Since the technique of Hara (2007a) is similar to that of $M_{\mathrm{wpd}}$, it is possible to determine magnitudes about 15 minutes after the origin time by this technique, when it is implemented on a real-time based system. Therefore, this technique would have produced a much better magnitude estimate than $M_{\mathrm{wp}}$, which is currently in place. It could have helped in getting a better picture of the size of the Tohoku earthquake earlier on. It is, therehore, highly desirable for the techninque to be operational before the next big earthquake.

The azimuthal dependence of the durations of HFER shown in Section 2 indicates the rupture propagation in a southwest direction, while some rupture models placed large slips in an east direction from the epicenter (e.g., Fujii et al., 2011; Hayes, 2011; Shao et al., 2011). These results suggest that there were two distinct rupture propagations in this event: one in a southwest direction from which high frequency energies were radiated efficiently, and the other in an east direction from which a very large seismic moment was released. The latter is likely to have cased the huge tsunamis that struck areas along the Sanriku coast.

Acknowledgments. In this study, we have used SAC (Seismic Analysis Code) (Goldstein et al., 2007) for seismic waveform data analyses. We appreciate the input of Dr. Anthony Lomax and an anonymous reviewer whose comments and suggestions greatly improved the original manuscript.

\section{References}

Bormann, P. and J. Saul, The new IASPEI standard broadband magnitude mB, Seismol. Res. Lett., 79, 698-705, doi:10.1785/gssrl.79.5.698, 2008. Chu, R. and D. Helmberger, High frequency analysis 3/11/2011 ( $M_{\mathrm{w}}$ 9.0), Tohoku-oki, Japan, http://www.tectonics.caltech.edu/slip history/2011_taiheiyo-oki/High_frequency/, 2011.

Fujii, Y., K. Satake, S. Sakai, M. Shinohara, and T. Kanazawa, Tsunami source of the 2011 off the Pacific coast of Tohoku Earthquake, Earth Planets Space, 63, this issue, 815-820, 2011.

Goldstein, P., D. Dodge, M. Firpo, L. Minner, J. E. Tull, D. Harris, and W. C. Tapley, SAC_-Seismic Analysis Code, http://www.iris.edu/manuals/ sac/manual.html, 2007.

Hara, T., Measurement of duration of high-frequency energy radiation and its application to determination of magnitudes of large shallow earthquakes, Earth Planets Space, 59, 227-231, 2007a.

Hara, T., Magnitude determination using duration of high frequency energy radiation and displacement amplitude: application to tsunami earthquakes, Earth Planets Space, 59, 561-565, 2007b.

Hara, T., Temporal characteristics of high band-pass filtered teleseismic $P$-waveforms from large shallow earthquakes, Earth Planets Space, 60 , 781-784, 2008

Hara, T., ERRATA: Magnitude determination using duration of high frequency energy radiation and displacement amplitude: application to tsunami earthquakes, Earth Planets Space, 61, 803-804, 2009.

Hayes, G. P., Rapid source characterization of the $2011 M_{\mathrm{w}} 9.0$ off the Pacific coast of Tohoku Earthquake, Earth Planets Space, 63, this issue, 529-534, 2011.

Ishii, M., High-frequency rupture properties of the $M_{\mathrm{w}} 9.0$ off the Pacific coast of Tohoku Earthquake, Earth Planets Space, 63, this issue, 609614, 2011.

Kanamori, H., Mechanism of tsunami earthquakes, Phys. Earth Planet. Inter, 6, 346-359, 1972.

Kanamori, H. and L. Rivera, Source inversion of W phase: speeding up seismic tsunami warning, Geophys. J. Int., 175, 222-238, doi:10.1111/j.1365-246X.2008.03887.x, 2008.

Lomax, A. and A. Michelini, $M_{\mathrm{wpd}}$ : A duration-amplitude procedure for rapid determination of earthquake magnitude and tsunamigenic potential from $P$ waveforms, Geophys. J. Int., 176, 200-214, 2009.

Lomax, A. and A. Michelini, Rapid mainshock location, magnitude and tsunami potential determinations in real-time at INGV, http://alomax.free.fr/posters/Japan_2011/Japan_2011_INGV_WarningM onitor.html, 2011.

Shao, G., X. Li, C. Ji, and T. Maeda, Focal mechanism and slip history of the $2011 M_{\mathrm{w}} 9.1$ off the Pacific coast of Tohoku Earthquake, constrained with teleseismic body and surface waves, Earth Planets Space, $\mathbf{6 3}$, this issue, 559-564, 2011.

Shearer, P. M. and P. S. Earle, The global short-period wavefield modelled with a Monte Carlo seismic phonon method, Geophys. J. Int., 158, 1103-1117, 2004.

Tsuboi, S., K. Abe, K. Takano, and Y. Yamanaka, Rapid determination of $M_{\mathrm{w}}$ from broadband P waveforms, Bull. Seismol. Soc. Am., 85, 606613, 1995

Tsuboi, S., P. M. Whitmore, and T. J. Sokolowski, Application of $M_{\mathrm{wp}}$ to deep and teleseismic earthquakes, Bull. Seismol. Soc. Am., 89, 1345$1351,1999$.

Wang, D. and J. Mori, Rupture process of the 2011 off the Pacific coast of Tohoku Earthquake $\left(M_{\mathrm{w}} 9.0\right)$ as imaged with back-projection of teleseismic $P$-waves, Earth Planets Space, 63, this issue, 603-607, 2011.

Whitmore, P. M., S. Tsuboi, B. Hirshorn, and T. J. Sokolowski, Magnitudedependent correction for $M_{\mathrm{wp}}$, Sci. Tsunami Hazards, 20, 187-192, 2002.

T. Hara (e-mail: thara@kenken.go.jp) 